\title{
Social Support and Patient Adherence to Medical Treatment: A Meta-Analysis
}

\author{
M. Robin DiMatteo \\ University of California, Riverside
}

\begin{abstract}
In a review of the literature from 1948 to 2001,122 studies were found that correlated structural or functional social support with patient adherence to medical regimens. Meta-analyses establish significant average $r$-effect sizes between adherence and practical, emotional, and unidimensional social support; family cohesiveness and conflict; marital status; and living arrangement of adults. Substantive and methodological variables moderate these effects. Practical support bears the highest correlation with adherence. Adherence is 1.74 times higher in patients from cohesive families and 1.53 times lower in patients from families in conflict. Marital status and living with another person (for adults) increase adherence modestly. A research agenda is recommended to further examine mediators of the relationship between social support and health.
\end{abstract}

Key words: patient adherence, social support, meta-analysis

The relationship between social support and health has received a great deal of research attention in health psychology and behavioral medicine (Kulik \& Mahler, 1989; Martin, Davis, Baron, Suls, \& Blanchard, 1994; Stone, Mezzacappa, Donatone, \& Gonder, 1999). Social support is an important factor in immune, endocrine, and cardiovascular functioning; recovery from illness and injury; and health maintenance (S. Cohen, 1988; DiMatteo \& Hays, 1981; Helgeson \& Cohen, 1996; Uchino, Cacioppo, \& Kiecolt-Glaser, 1996; Wallston, Alagna, DeVellis, \& DeVellis, 1983). The precise means by which social support contributes to health and the factors that moderate and mediate this relationship are not yet completely understood (Stone et al., 1999; Vitaliano et al., 2001). Social support may benefit health by buffering stress, influencing affective states, and/or changing behaviors (S. Cohen, 1988); direct effects may occur with hormonal and neuroendocrine influences on the immune system, and indirect effects may occur through lifestyle and health behaviors (Connell, Davis, Gallant, \& Sharpe, 1994) or other aspects of social and psychological functioning (e.g., depression; DiMatteo, Lepper, \& Croghan, 2000; Goodenow, Reisine, \& Grady, 1990). Social support also influences the ability to adjust to and live with illness (Hegelson \& Cohen, 1996; Taylor, Falke, Shoptaw, \& Lichtman, 1986). Further, social support has many facets that may contribute uniquely to the illness puzzle (Martin et al., 1994; Wallston et al., 1983).

Patient adherence may well mediate the link between social support and health (Dunbar-Jacob \& Schlenk, 2001). Adherence

Additional materials are on the Web at http://dx.doi.org/10.1037/0278 -6133.23.2.207.supp

This research was supported by the Committee on Research and the Center for Ideas and Society at the University of California, Riverside, and by Eli Lilly and Company. I thank Heidi Lepper and David Payesteh for their assistance in searching the literature and Patrick Giordani for his advice on the meta-analytic procedures used in this work.

Correspondence concerning this article should be addressed to M. Robin DiMatteo, Department of Psychology, University of California, Riverside, CA 92521. E-mail: robin@ citrus.ucr.edu (or compliance) involves patient acceptance and follow-through with treatment recommendations. An appreciable number of patients (as many as 25\%-40\%) are nonadherent (DiMatteo, 1994, 2000; Dunbar-Jacob \& Schlenk, 2001), and adherence has been found to have significant effects on treatment outcomes (DiMatteo, Giordani, Lepper, \& Croghan, 2002). Assistance and support from friends and family have been implicated in promoting patient adherence by encouraging optimism and self-esteem, buffering the stresses of being ill, reducing patient depression, improving sickrole behavior, and giving practical assistance (Shumaker \& Hill, 1991; Wallston et al., 1983). The establishment of a significant and substantial relationship between social support and adherence would suggest adherence as an important mediating mechanism between social support and health outcomes.

There is promising empirical verification for the social supportadherence connection, although the research results are contradictory and complex (Burroughs, Harris, Pontious, \& Santiago, 1997; Uchino et al., 1996; Wallston et al., 1983). Establishing the precise strength and nature of this connection requires quantitative methods for summarizing the empirical literature (Hunt, 1997; Rosenthal, 1991; Rosenthal \& DiMatteo, 2001, 2002). Several meta-analyses have already begun to delineate quantitatively the central role played by social support in health outcomes (Devine \& Pearcy, 1996; Meyer \& Mark, 1995; Mullen, Mains, \& Velez, 1992; Uchino et al., 1996). These need to be extended further, taking into account adherence and the variables that may moderate the support-adherence relationship, such as the type of social support (structural vs. functional, practical vs. emotional), the patient's disease and treatment regimen, and methodological variables (e.g., the types and reliability of measures; Heitzmann \& Kaplan, 1988; Helgeson \& Cohen, 1996; Kaplan \& Hartwell, 1987; Martin et al., 1994).

Quantitative investigation of the effects of both structural (e.g., marital status, living arrangement) and functional (e.g., practical/ instrumental, emotional, family cohesion) social support (Uchino et al., 1996) on adherence is essential to understanding its role in 
patient health (Goodenow et al., 1990; Shumaker \& Hill, 1991). This article presents a quantitative review of all published empirical journal articles relating the adherence of medical patients to these several aspects of social support. This research has the following goals: (a) to summarize, using techniques of metaanalysis, the strength and statistical significance of the relationship of patient adherence (in medical treatment for a variety of diseases and conditions) to three categories of perceived functional social support (practical, emotional, and unidimensional/undifferentiated) and measures of family structure (marital status and living arrangement) and functioning (family cohesiveness, family conflict); and (b) to examine, using meta-analytic techniques, both methodological and substantive moderators of the relationships between adherence and social support, family structure, and family functioning.

\section{Method}

\section{Search Strategy}

The medical and psychological literature was searched for empirical studies correlating adherence with patients'-or parents', in the case of pediatric patients-(a) marital status and living arrangement (providing a partial representation of the domain of structural support), and (b) practical, emotional, and unidimensional social support, and family cohesiveness and conflict (providing a partial representation of functional social support; Uchino et al., 1996). This review spans research from 1948 through March 2001. Beginning with research from 1966, the main search strategy involved electronic measures using keywords patient compliance and patient adherence in the PsychLit and (core medical journal) Medline databases. The literature before 1966 was available in printed volumes of Index Medicus. Index searches were supplemented with citations culled from the reference sections of each article consulted. Additional terms for the adherence construct were also searched for: acceptance of medical recommendations, failure to receive medication, follow-up of medical recommendations, medication omission errors, and patient defection from therapy.

Only articles published in peer-reviewed, English-language journals retrieved by the above strategy were included (omitting book chapters, dissertations, non-peer-reviewed journal articles, and conference proceedings). Studies involved only physician-generated recommendations for medical treatment and the medical patient's adherence (or nonadherence) to it. Studies with sample size greater than 10 were included only if they precisely behaviorally defined the construct of adherence (e.g., taking medication correctly) and its method and format of measurement (e.g., self-report rating scale), and if they reported the correlation between adherence and one or more of the following elements of structural or functional social support: practical support, emotional support, unidimensional social support (combining all types into a single measure), family cohesiveness, family conflict/dysfunction, marital status, and living arrangement (alone or with others). If this correlation was not provided, but the raw data or a statistic such as $t, F$, or chi-square sufficient to calculate it was provided, the study was included. Interventions designed to increase patient adherence were excluded in order to examine naturally occurring adherence in clinical practice. Studies involving psychiatric patients, psychiatric regimens, or treatments provided by psychiatrists were also excluded. Psychiatric treatment regimens (including those for depression) are widely prescribed, and adherence to them is a very relevant issue; study of the social support correlates of adherence within the realm of nonpsychiatric medical treatment was considered sufficiently complex to warrant its sole focus in the present study. Studies of patients with alcoholism or drug abuse and of homeless or institutionalized patients were excluded for similar reasons, and military personnel were excluded because of potential institutional controls on adherence. Finally, the focus of the present research is on recommendations made in the physician-patient relationship; therefore, studies of adherence to community screening procedures and vaccination programs, to commercial weight-loss programs, and to community-based exercise programs were not included. Repeated crosschecking of references within the larger adherence meta-analysis project of which this study is a part suggests that the vast majority, if not all, of the articles meeting the criteria for inclusion were found (see also, DiMatteo, 2004; DiMatteo et al., 2000, 2002). Care was taken to avoid overlap or repetition of samples from a given research group or laboratory. A total of 122 empirical journal articles met the inclusion/exclusion criteria.

\section{Organization of Studies}

Each of the 122 articles offered data on at least one social support correlate of adherence. Appendix A, which is available on the Web at http://dx.doi.org/10.1037/0278-6133.23.2.207.supp, presents 29 studies of the relationship between adherence and practical social support (e.g., instrumental support, assistance, reminders, organization, support for a specific behavior), 11 studies of adherence and emotional social support (e.g., emotional support, nurturance), and 28 studies of adherence and unidimensional social support (involving multiple types not separated in their measurement; King, Reis, Porter, \& Norsen, 1993). Appendix A also presents 14 studies of adherence and family cohesiveness (e.g., warmth, closeness, acceptance) and 6 of adherence and family conflict/dysfunction. Appendix B, which is available on the Web at http://dx.doi.org/10.1037/ 0278-6133.23.2.207.supp, presents both marital status (51 studies) and living arrangement (22 studies) as correlates of patient adherence. The living arrangement studies are further divided into 17 of adult patients that involve living with someone else versus living alone, and 5 of pediatric patients that involve the number of people, including siblings, who are living in the child's household. Several of the 122 articles provided independent data for more than one variable of interest, and some presented more than one independent sample. For each reference, the following information was coded and used in the analysis of moderators: the disease for which care was provided, the details of the method for assessing adherence, the regimen requiring adherence, the social support measure used, the sample size, the age group studied (adult, pediatric, or both), and the $r$ (correlation) effect size between the adherence and the social support measure.

\section{Statistical Analyses}

The $r$ effect size was either provided in each article or computed from $t$, $F$, chi-square, summary statistics, or contingency table data (phi; Rosenthal \& Rosnow, 1991). If the effect size presented in an article had more than one degree of freedom, phi was calculated if the data were available. If not, the exact probability was converted to the $z$ statistic and then transformed to $r$. Absent the exact probability, these one-tailed $z$ s were used: $\mathrm{z}=1.645$ for $p<.05, \mathrm{z}=2.326$ for $p<.01$, and $\mathrm{z}=3.09$ for $p<.001$. When results were reported as nonsignificant with no data available, $\mathrm{z}=.00$ was assigned, although it is a conservative estimate. Some studies used several measures of adherence and examined several outcomes, providing multiple data points that were averaged (also a conservative approach).

For each study (unit of analysis) in Appendixes A and B (available on the Web at http://dx.doi.org/10.1037/0278-6133.23.2.207.supp), the effect size used was the correlation coefficient $r$, which represents the strength and direction of the association between the measure of adherence and the measure of structural or functional social support (Rosenthal, 1991). Positive effect sizes reflect the association of greater adherence with higher scores on the labeled variable. For each group of studies presented, the unweighted mean $r$ (equivalent to the risk difference) was computed for each social support variable by using Fisher's $z$ transformation of the $r$ effect sizes. The standardized odds ratio was calculated from this un- 
weighted mean by using the binomial effect-size display (Rosenthal, Rosnow, \& Rubin, 2000). The transformation of the average $r$ into average Cohen's $d$ was also calculated in order to provide a measure of the standard deviation $(S D)$ difference (J. Cohen, 1988). Confidence intervals (95\%) were calculated for each risk difference (unweighted mean $r$ ) and for each odds ratio on the basis of a random effects model.

Variations among the $r$ effects in each table were appraised, and both methodological and substantive moderators were assessed to explain these variations (Rosenthal \& DiMatteo, 2001). The fail-safe $n$ (the number of unretrieved studies that would need to average no effect in order to reduce a finding significant at the .05 alpha level to nonsignificance) was calculated for each average effect size that reached significance (Rosenthal, 1979; Rosenthal \& Rosnow, 1991).

To examine the potential role of moderators in the social supportadherence relationship, we coded each study according to the following: year the study was published (as a measure of recency), type of disease (acute/chronic), seriousness of disease (according to the Seriousness of Illness Rating Scale-Revised; Rosenberg, Hayes, \& Peterson, 1987), type of regimen (nonmedication/medication), number of regimens to which patients' were expected to adhere (one/more than one), number of methods used to measure patients' adherence (one/more than one), whether selfreport was used to measure adherence (no/yes), age group of the sample (pediatric/adult), and sample size. Two coders assessed the moderators for each study, and any disagreements were negotiated before assigning a code. For moderators with continuous measurement, such as disease severity, relationships to effect size were assessed with Pearson productmoment correlation coefficients in a random effects model. For dichotomous moderators, unweighted mean effect sizes were compared between the two levels by means of $t$ (random effects model) and $z$ (fixed effects model) statistics. Correlations among the moderator variables were computed and examined in order to recognize any that may have been redundant.

In the present research, the determination of whether an average effect size is significantly different from zero is always based on the stringent random effects model that requires unconditional inferences and allows generalization beyond the studies sampled. Fixed effects allow conditional inferences that apply only to the set of studies observed or to identical ones and, while limited, can also be informative (Hedges \& Vevea, 1998; Howell, 1997). In this research, comparisons between levels of the moderator variables use both fixed and random approaches in order to clarify the relative strength of these moderators of the social support-adherence relationship.

\section{Results}

Table 1 presents the meta-analysis results for each of the social support variables and their moderators. Nearly all bear significant, and in many cases quite strong, relationships to adherence.

\section{Practical Support}

Across 29 studies of practical social support and adherence, correlations range from -.22 to .75 . The median (.27) and the unweighted mean effect size $r(.31)$ are close in magnitude, and the mean is highly significant in the random effects model. This suggests a strong overall positive correlation between adherence and practical social support, with a $0.65 S D$ difference in adherence between patients receiving practical support for their treatment regimen and those not receiving such support. The standardized odds ratio demonstrates that the odds of adherence (compared with nonadherence) are 3.60 times higher among those who receive practical support than among those who do not, and the standardized relative risk specifies that the risk for nonadherence is almost twice as high among patients who do not receive practical support as among those who do. The fail-safe $n$ confirms that there would need to exist over 1,800 unpublished or otherwise unretrieved research papers somewhere (in file cabinets, perhaps) that found, on average, no effect of practical support on adherence to render this result nonsignificant at the .05 alpha level.

As noted in the last column of Table 1, analysis of variation among the 29 effect sizes yields two significant moderators. Smaller samples yield significantly higher correlations of practical support with adherence than do larger samples (random effects). Studies using self-reports of adherence yield higher correlations between practical support and adherence (average $r=.35$ ) than studies not using self-report (average $r=.20$; fixed effects).

\section{Emotional Support}

There are 11 studies of emotional support and patient adherence with $r$ effect sizes ranging from .00 to .37 . The median and mean are identical (.15), the latter being strongly significant. There is a $0.30 S D$ difference in adherence between patients receiving emotional support and patients not receiving emotional support. The risk of nonadherence is 1.35 times higher if patients do not receive emotional support than if they do, and this finding is fairly robust, requiring at least 93 unretrieved studies with null findings to render it nonsignificant. Analysis of moderators yields one that is significant (fixed effects model). The relationship between emotional support and adherence is higher in studies using self-reports of adherence (average $r=.19$ ) than in studies not using selfreports (average $r=.06$ ).

\section{Unidimensional Social Support}

For 27 studies, the measurement of social support is unidimensional, not allowing separation of the dimensions (King et al., 1993). Correlations with adherence range from -.06 to .60 , and the median and mean effect sizes are similar (.20 and .21, respectively), with the latter achieving statistical significance $(p<.001)$. There is a $0.43 S D$ difference in adherence between high and low levels of social support, and the odds of adherence are 2.35 times higher with greater levels of support. The risk of nonadherence is 1.53 times higher among patients with low social support, and the significance of the relationship between unidimensional social support and adherence would be called into question only if there were over 1,000 unretrieved studies of this relationship (unlikely given the exhaustive nature of the search process used in this review). Social support has a greater effect on adherence in studies requiring more than one regimen for patients to adhere to than in studies requiring only one regimen (random effects).

\section{Family Cohesiveness and Family Conflict}

All 14 studies of family cohesiveness (including warmth, acceptance, family emotional health, and closeness) yield positive correlations with adherence, and their respective median and mean are .25 and .27 (significant at the .001 level). There is a $0.56 S D$ difference in adherence between patients who are in cohesive families and those who are not. The odds of adhering are 3.03 times higher among patients in close and cohesive families, and the risk of nonadherence is 1.74 times higher among patients reporting 


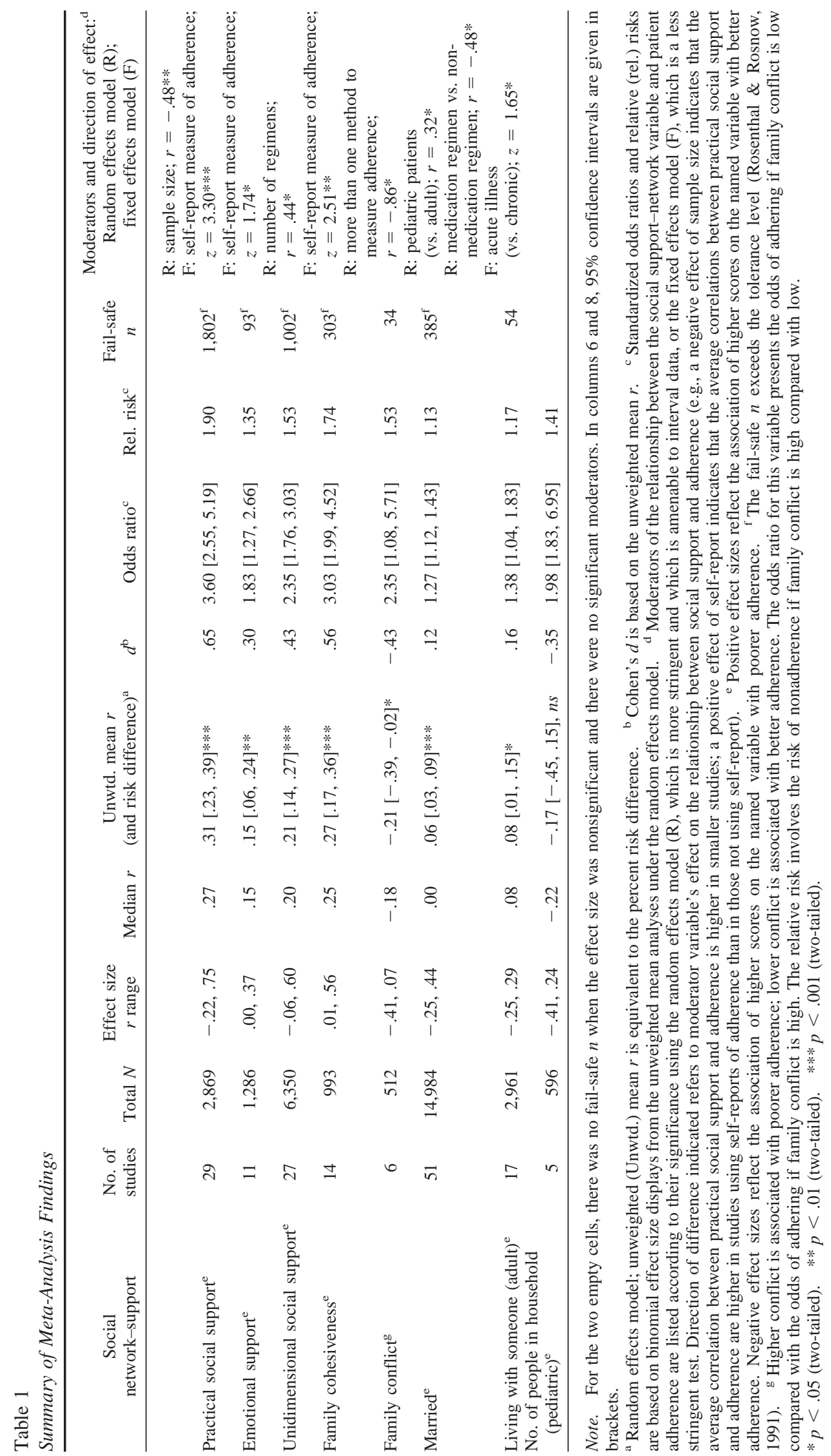


low levels of family cohesion than among those reporting high levels. The fail-safe $n$ of 303 makes these findings fairly robust. The effect of family cohesiveness on adherence is moderated only by a fixed effects variable: Studies using self-reports of adherence have higher adherence-family cohesiveness effect sizes than those not using self-reports (average $r=.34$ vs. .16, respectively).

There are six studies of family conflict (including dysfunctional interaction and pathology), with effects ranging from -.41 to .07 and a median of -.18 . A significant average $r$ effect size of -.21 indicates that poorer adherence is associated with greater family conflict (although the fail-safe $n$ is only 34, indicating a finding that is not as robust as others in this review). Patient adherence is $0.43 S D$ lower in families with higher conflict, and the odds of nonadherence among patients in higher conflict families are 2.35 times higher than among those in families with lower levels of conflict. The risk of nonadherence is 1.53 times higher if there is high conflict in the patient's family than if there is not. In studies using more than one method to measure adherence, family conflict has a more detrimental effect on adherence than in studies using only one method of measuring adherence (random effects).

\section{Marital Status}

Fifty-one studies correlating marital status with adherence produced effect sizes ranging from -.25 to .44 , with a median of .00 . Because of the large number of studies, the mean $r$ of .06 is significant ( $p<.001$ level) and fairly robust (fail-safe $n=385$ ). The difference between the married and unmarried distributions is only $.12 S D$, the odds of adhering if married are 1.27 times higher than if unmarried, and the risk of nonadherence is 1.13 times higher among unmarried subjects than among married subjects. One moderating variable, age group of the sample, is significant (random effects). Among 40 studies of adult patients, the average correlation between subjects' marital status and their adherence is .05. Among 9 samples of pediatric patients, however, the average correlation between parents' marital status and children's treatment adherence is .15 . The risk of nonadherence among children with unmarried parents is 1.35 times higher (standardized relative risk from the binomial effect-size display) than the risk of nonadherence among children with married parents.

\section{Living Arrangement}

Twenty-two studies correlated patients' adherence with their living arrangement. For 17 samples of adults, this variable involved whether patients lived alone or with at least one other person; for five studies of pediatric patients, it involved the number of persons living in the household, including siblings. For adults, living with someone had a positive effect on adherence (median and mean $r=.08, p<.05$ ). The odds of adherence among adults living with others were 1.38 times higher than among those living alone, and the relative risk of nonadherence was 1.17 times higher among those living alone (not a robust result, as the fail-safe $n$ of 54 does not exceed the critical level; Rosenthal \& Rosnow, 1991). A significant random effects moderator is medication. Living with someone had a more positive effect on adherence to behavioral regimens than to medication regimens. A significant fixed effects moderator was type of illness. Living with someone had a higher effect on adherence in acute illness (mean $r=.25$ ) than in chronic illness (mean $r=.04$ ). Among children, the average correlation between adherence and the number of people living in the household is -.17 (the more people, including siblings, the lower the adherence), although this trend does not reach significance. More studies would be needed to establish a clear relationship, but it appears from these five effect sizes, four of which are negative, that the role of children's living arrangement in their adherence is worthy of further study.

\section{Comparing Structural and Functional Social Support}

The average correlations between adherence and three types of functional social support (practical, emotional, and family cohesiveness) were compared with the average correlations between adherence and structural social support (marital status and living arrangement of adults). The adherence-functional social support relationship is significantly stronger than the marital statusadherence relationship for all three functional social support categories: practical support, $t(78)=6.26, p=.0001$; emotional support, $t(60)=2.16, p=.035$; family cohesiveness, $t(63)=5.20$, $p=.000$. The adherence-functional social support relationship is significantly stronger than the adherence-living arrangement relationship for both practical support, $t(44)=3.70, p=.001$, and family cohesiveness, $t(29)=3.44, p=.002$. The relationship of adherence to emotional support is higher than it is to living arrangement, but not significantly, $t(26)=1.37, p=.18$. Thus, functional measures of social support tend to be more highly related to adherence than do structural measures.

There are differences among the types of functional social support in their connection to adherence. Practical support yields, on average, significantly higher effects than emotional support, $t(38)=2.09, p<.05$. There is also a trend for practical support to yield higher effects than unidimensional support, which typically involves a combination of practical and emotional support, $t(54)=$ $1.96, p<.10$. The five studies (see Appendix A on the Web at http://dx.doi.org/10.1037/0278-6133.23.2.207.supp) that provided effect sizes for both emotional support and practical support were examined. In three of them, the effect sizes for practical support are higher; in two, emotional support bears a stronger relationship with adherence, $t(4)=0.47, n s$. Finally, practical and unidimensional support do not differ from family cohesiveness in their relationship to adherence, but there is a trend such that family cohesivenss has a somewhat stronger relationship to adherence than does emotional support, $t(23)=1.89, p=.07$.

\section{Discussion}

This meta-analysis summarizes empirical research on the association of two central topics in health psychology: social support and patient adherence to medical treatment. During the past 5 decades, research on both topics has been abundant, and examination of their association and its substantive and conceptual moderators has been enlightening. This meta-analysis involves a broad base of subjects, various disease conditions, and different patient ages, treatment regimens, and measurement strategies. There is surprising consistency in the social support-adherence effects. These effects suggest that the pathway from social support to health likely travels through patient adherence (Druley \& Townsend, 1998; Hagedoorn et al., 2000; Martin, et al., 1996). 
Further, where there is appreciable variability, the identification and exploration of substantive and methodological moderators has been very instructive.

There are specific limitations in the present work; in the current state of the literature; and, more generally, in meta-analysis. These limitations introduce caveats to the interpretation of the findings. First, a limited number of papers meet the inclusion/exclusion criteria, and despite great care taken to retrieve all of the relevant studies in the literature, some may have been missed. This metaanalysis is limited to medical patients and excludes psychiatric care, which presents a particular challenge to adherence (DiMatteo, 1999). Second, there is a greater likelihood that significant results will be published in the literature, although the fail-safe $n$ provides a correction for the possible existence of unpublished studies with nonsignificant effects. It is not possible, however, to correct for potential biases among researchers toward conducting studies only on diseases or regimens for which certain social support-adherence effects might be expected. Third, there is considerable variation in the conceptualization and measurement of social support, and coding decisions regarding social support types and moderators, although made on the basis of definitions and conventions in the literature, were nevertheless subjective. Fourth, most effect sizes available and all those reported here are linear. Potential curvilinear effects should be further explored, because too much social support may be as bad as too little (fostering overprotection, limiting active engagement, etc.; Goodenow et al., 1990; Hagedoorn et al., 2000; Martin et al., 1994). Relatedly, few studies provide data on gender as a potentially important moderator of the social support-adherence relationship (Shumaker \& Hill, 1991). Fifth, the studies in this meta-analysis are all correlational and typically retrospective, making causal inferences impossible (Wallston et al., 1983). Although social support likely influences adherence, it is also possible that adherence influences social support, with individuals who adhere receiving more support for their efforts than those who do not. A third variable (e.g., personality, resources) may be responsible, particularly for some medical conditions and regimens (Connell \& D' Augelli, 1990; DiMatteo \& Martin, 2002). Sixth, unlike large-scale multidimensional studies, in meta-analysis it is not possible to assess the impact of moderators and covariates within studies. There is evidence across many fields that multidimensional and meta-analytic studies usually tell the same story (Ioannidis, Cappelleri, \& Lau, 1998), but there exists a general problem in pooling results from observational studies because confounding and moderating variables are implicit in the statistics presented. In the present research, it is possible to account for moderating variables only across studies, not within them (DiMatteo et al., 2002). Relatedly, the studies available in the literature on the social support-adherence relationship allow for its conceptual organization only into broad categories (such as family cohesiveness). The specific interplay of sources and types of support (e.g., practical support from the spouse or parents, emotional support from friends) are not spelled out in enough studies to examine their differential effects on adherence (Hagedoorn et al., 2000; La Greca et al., 1995; La Greca, Bearman, \& Moore, 2002; Revenson \& Majerovitz, 1991). Finally, these results are influenced by the measures used in the studies available, including their conceptual meaning, reliability, and validity (Heitzmann \& Kaplan, 1988). For example, practical support, emotional support, and family cohesiveness correlated higher with self-report mea- sures of adherence than with non-self-report measures. This might be explained by the self-report nature of many social support measures, although across the three categories, the Kendall's tau rank-order correlation between the mean effect size and the percentage of studies that measured adherence by self-report was zero. At least at the aggregate level, there is no evidence that the mean effect is a result of the use of self-reports of adherence. Relatedly, an important theoretical distinction within the social support literature is whether the support is perceived to be available or instead has been provided (Bolger, Zuckerman, \& Kessler, 2000), the latter potentially extracting an emotional cost and leading to poorer adjustment because of reduced esteem or ineffective support attempts. Recoding of the measures used to assess practical, emotional, and unidimensional social support revealed no differences between perceived available support and received support: practical, $t(23)=-0.68, n s$; emotional, $t(7)=-0.79, n s$; unidimensional, $t(17)=1.03$, ns. Of course, this potentially important distinction may not receive a fair test using the aggregate data available from meta-analysis, and requires closer examination in numerous primary data-collection settings.

In spite of the above caveats and limitations, the results of this meta-analysis provide solid quantitative evidence that social support has substantial effects on patient adherence and, just as they do on physiological regulation and morbidity/mortality outcomes, these effects vary with different types of social support (Goodenow et al., 1990; Helgeson \& Cohen, 1996; Kulik \& Mahler, 1989; Seeman, Lusignolo, Albert, \& Berkman, 2001; Shumaker \& Hill, 1991; Uchino et al., 1996; Vitaliano et al., 2001). Functional social support has stronger effects on adherence than does structural social support, suggesting that the mere presence of other people does not matter as much as the quality of relationships with them. Furthermore, social support may not be universally helpful; its value may depend at least partially on situational demands such as the type and severity of the illness and the complexity of the regimen (Martin et al., 1994; Penninx et al., 1998), and even on the type of measures used in the research (Heitzmann \& Kaplan, 1988).

It is valuable to explore a tentative model of the mechanisms by which social support and adherence are linked in order to guide future research on adherence and to more fully understand social support and its parameters (S. Cohen 1988; Reifman, 1995). Social support may buffer stress and allow an individual to engage in more adaptive sick-role behaviors and take positive action toward adherence (Wallston et al., 1983). The presence of close others may result in the direct or indirect control of behavior, facilitating adherence through internalization of norms and the provision of sanctions for deviating from behavior that is conducive to health (the social control hypothesis; Lewis \& Rook, 1999; Umberson, 1987). Conversely, a nonsupportive social network can interfere with successful alteration of health habits by limiting the patient's time and energy available for health behavior (Kaplan \& Hartwell, 1987) or introducing stress that compromises the attitudes and behaviors necessary for adherence (Revicki \& May, 1985). Social support might affect adherence through physiological mechanisms such as immune, endocrine, and cardiac functioning (Druly \& Townsend, 1998) or through increased patient satisfaction with medical care (Da Costa et al., 1999). Social support may improve patient adherence through improved cognitive functioning, selfefficacy, intrinsic motivation, personal control, confidence, self- 
esteem, and mood, as well as through reduced emotional conflict, interpersonal strain, distress, and depression (Alferi, Carver, Antoni, Weiss, \& Duran, 2001; Allgower, Wardle, \& Steptoe, 2001; DiMatteo et al., 2000; Druley \& Townsend, 1998; Glasgow et al., 1989; Goodenow et al., 1990; Holahan, Moos, Holahan, \& Brennan, 1995; King et al., 1993; Kulik \& Mahler, 1993; McBride et al., 2001; Schneider, Friend, Whitaker, \& Wadhwa, 1991; Seeman et al., 2001; Taal, Rasker, Seydel, \& Wiegman, 1993). The complete picture of how social support affects health, both directly and indirectly, is likely quite complicated; its exploration requires the kind of meticulous scrutiny of the empirical research that metaanalytic techniques, in their broadest configuration, allow.

Although patient adherence is an excellent candidate for a potent and straightforward mediator of the stress-health connection, it is important to consider more complex connections as well. As one example, patient depression is strongly related to both social support and patient adherence, and may be a mediator between them. Substantive and methodological variables, including type of social support, disease condition, regimen, and measurement strategy, may further moderate these connections (Connell et al., 1994; DiMatteo et al., 2000, 2002; Penninx et al., 1998). In another example, practical support may lead directly and straightforwardly to adherence, whereas emotional social support may lead first to increased self-esteem and then to better adherence (directly, or indirectly through lower depression; Connell et al., 1994). (This direct effect of practical support may account for its higher correlation with adherence than that of emotional support, which may have an indirect effect.) Stress likely plays a crucial role as well (S. Cohen, 1988). Although the present research illuminates one of the possible pathways from social support to health by documenting the social support-adherence connection, each potential pathway in what is likely a complicated model needs eventually to be understood. Much future research is necessary in order to complete this complex puzzle.

This review and meta-analysis suggests several issues relevant to future research and application. It contributes evidence for the importance of social support to the enhancement of adherence. Using the binomial effect-size display (see Rosenthal \& DiMatteo, 2001), the present results on practical support, for example, show that among every 100 patients who are not receiving practical help with their treatment regimens, at least 65 can be expected to be noncompliant (instead of a 50/50 split if there were no relationship between adherence and practical support). In light of the exceedingly large number of patients who are nonadherent in medical practice, practical support is a potentially important target for interventions to reduce health care costs and improve health. This research suggests that in the clinical setting, it is important to assess the type and quality of a patient's relationships in order to assist him or her to receive the most benefit from medical treatment. Whereas living alone, for example, might put a patient at slightly increased risk for nonadherence (particularly to nonmedication regimens), living in a family that is in conflict may increase the risk of nonadherence considerably. These results also suggest the importance of identifying the potentially detrimental effects on adherence (and ultimately on health outcomes) of the absence or erosion of patients' social support over the course of the illness, and the importance of designing interventions to improve adherence that include practical help in the context of an emotionally supportive and cohesive network.
In research, more systematic empirical study is needed, including multidimensional longitudinal research (such as work by Fontana, Kerns, Rosenberg, \& Colonese, 1989). More comprehensive quantitative reviews and multifactor studies, particularly those that allow comparisons among various types of acute and chronic conditions, are also needed to determine exactly how social support works to affect adherence to treatment and ultimately to influence health, health care utilization, and health care costs (Pilisuk, Boylan, \& Acredolo, 1987). Researchers need to examine the presence of nonlinear trends and possible third variables, and to specify the kind of social support that is of value, its sources, and its specific adherence targets. Future research should carefully focus on moderators of the social support-adherence relationship and determine how measurement, disease characteristics and severity, regimen, and patient characteristics affect results. It is important that primary data-collection studies include a consistent set of both substantive and methodological moderators within each study so that they can be meaningfully compared across studies. This article provides a template for examination of some of these moderators and a step toward understanding the connections between social support and adherence, which are two of the most complicated constructs that health psychologists deal with, and ones that promise great potential to improve health and well being.

\section{References}

References marked with an asterisk indicate studies included in the meta-analysis.

*Abbott, J., Dodd, M. B. D., \& Webb, A. K. (1994). Treatment compliance in adults with cystic fibrosis. Thorax, 49, 115-120.

Alferi, S. M., Carver, C. S., Antoni, M. H., Weiss, S., \& Duran, R. E. (2001). An exploratory study of social support, distress, and life disruption among low-income Hispanic women under treatment for early stage breast cancer. Health Psychology, 20, 41-46.

Allgower, A., Wardle, J., \& Steptoe, A. (2001). Depressive symptoms, social support, and personal health behaviors in young men and women. Health Psychology, 20, 223-227.

*Al-Shammari, S. A. (1992). Failures to keep primary care appointments in Saudi Arabia. Family Practice Research Journal, 12, 171-176.

*Anderson, B. J., Auslande, W. F., Jung, K. C., Miller, J. P., \& Santiago, J. V. (1990). Assessing family sharing of diabetes responsibilities. Journal of Pediatric Psychology, 15, 477-492.

*Anderson, B., Ho, J., Brackett, J., Finkelstein, D., \& Laffel, L. (1997) Parental involvement in diabetes management tasks: Relationships to blood glucose monitoring adherence and metabolic control in young adolescents with insulin-dependent diabetes mellitus. Journal of Pediatrics, 130, 257-265.

*Anson, O., Weizman, Z., \& Zeevi, N. (1990). Celiac disease: Parental knowledge and attitudes of dietary compliance. Pediatrics, 85, 98-103.

*Arnsten, J. H., Gelfand, J. M., \& Singer, D. E. (1997). Determinants of compliance with anticoagulation: A case-control study. American Journal of Medicine, 103, 11-17.

*Bame, S. I., Petersen, N., \& Wray, N. P. (1993). Variation in hemodialysis patient compliance according to demographic characteristics. Social Science and Medicine, 37, 1035-1043.

*Bastone, E. C., \& Kerns, R. D. (1995). Effects of self-efficacy and perceived social support on recovery-related behaviors after coronary artery bypass graft surgery. Annals of Behavioral Medicine, 17, 324 330 .

*Beaulieu, M., Beland, F., Roy, D., Falardeau, M., \& Hebert, G. (1996). Factors determining compliance with screening mammography. Canadian Medical Association Journal, 154, 1335-1343. 
*Becker, M. H., Drachman, R. H., \& Kirscht, J. P. (1972). Predicting mothers' compliance with pediatric medical regimens. Journal of Pediatrics, 81, 843-854.

*Belgrave, F. Z., \& Lewis, D. M. (1994). The role of social support in compliance and other health behaviors for African Americans with chronic illnesses. Journal of Health \& Social Policy, 5, 55-68.

*Berger, D., Braverman, A., Sohn, C. K., \& Morrow, M. (1988). Patient compliance with aggressive multimodal therapy in locally advanced breast cancer. Cancer, 61, 1453-1456.

*Blackburn, S. L. (1977). Dietary compliance of chronic hemodialysis patients. Journal of the American Dietetic Association, 70, 31-37.

Bolger, N., Zuckerman, A. \& Kessler, R. C. (2000). Invisible support and adjustment to stress. Journal of Personality and Social Psychology, 79, 953-961.

*Borkman, T. S. (1976). Hemodialysis compliance: The relationship of staff estimates of patients' intelligence and understanding to compliance. Social Science and Medicine, 10, 385-392.

*Botelho, R. J., \& Dudrac, R. (1992). Home assessment of adherence to long-term medication in the elderly. Journal of Family Practice, 35, $61-65$.

*Boyer, C. B., Friend, R., Chlouverakis, G., \& Kaloyanides, G. (1990). Social support and demographic factors influencing compliance of hemodialysis patients. Journal of Applied Social Psychology, 20, 19021918.

*Brand, F. N., Smith, R. T., \& Brand, P. A. (1977). Effect of economic barriers to medical care on patients' noncompliance. Public Health Reports, 92, 72-78.

*Brewer, B. W., Van Raalte, J. L., Cornelius, A. E., Petitpas, A. J., Skilar, J. H., Pohlman, M. H., et al. (2000). Psychological factors, rehabilitation adherence, and rehabilitation outcome after anterior cruciate ligament reconstruction. Rehabilitation Psychology, 45, 20-37.

Burroughs, T. E., Harris, M. A., Pontious, S. L., \& Santiago, J. V. (1997). Research on social support in adolescents with IDDM: A critical review. The Diabetes Educator, 23, 438-448.

*Burroughs, T. E., Pontious, S. L., \& Santiago, J. V. (1993). The relationship among six psychosocial domains, age, health care, adherence, and metabolic control in adolescents with IDDM. Diabetes Educator, 19, $396-402$

*Carpenter, J. O., \& Davis, L. J. (1976). Medical recommendationFollowed or ignored? Factors influencing compliance in arthritis. Archives of Physical Medicine and Rehabilitation, 57, 241-246.

*Catz, S. L., Heckman, T. G., Kochman, A., \& DiMarco, M. (2001). Rates and correlates of HIV treatment adherence among late middle-aged and older adults living with HIV disease. Psychology, Health, \& Medicine, 6, 47-58.

*Catz, S. L., Kelly, J. A., Bogart, L. M., Benotsch, E. G., \& McAuliffe, T. L. (2000). Patterns, correlates, and barriers to medication adherence among person prescribed new treatments for HIV disease. Health Psychology, 19, 124-133.

*Catz, S. L., McClure, J. B., Jones, G. N., \& Brantley, P. J. (1999). Predictors of outpatient medical appointment attendance among persons with HIV. AIDS Care, 11, 361-373.

*Chaney, J. M., \& Peterson, L. (1989). Family variables and disease management in juvenile rheumatoid arthritis. Journal of Pediatric Psychology, 14, 389-403.

*Christensen A. J., Smith, T. W., Turner, C. W., Holman, J. W., Gregory, M. C., \& Rich, M. A. (1992). Family support, physical impairment, and adherence in hemodialysis: An investigation of main and buffering effects. Journal of Behavioral Medicine, 15, 313-325.

*Christiaanse, M. E., Lavigne, J. V., \& Lerner, C. V. (1989). Psychosocial aspects of compliance in children and adolescents with asthma. Journal of Developmental and Behavioral Pediatrics, 10, 75-80.

Cohen, J. (1988). Statistical power analysis for the behavioral sciences (2nd ed). Hillsdale, NJ: Erlbaum.
Cohen, S. (1988). Psychosocial models of the role of social support in the etiology of physical disease. Health Psychology, 7, 269-297.

*Col, N., Fanale, J. E., \& Kronholm, P. (1990). The role of medication noncompliance and adverse drug reactions in hospitalizations of the elderly. Archives of Internal Medicine, 150, 841-845.

Connell, C. M., \& D'Augelli, A. R. (1990). The contribution of personality characteristics to the relationship between social support and perceived physical health. Health Psychology, 9, 192-207.

Connell, C. M., Davis, W. K., Gallant, M. P., \& Sharpe, P. A. (1994). Impact of social support, social cognitive variables, and perceived threat on depression among adults with diabetes. Health Psychology, 13, 263-273.

*Coons, S. J., Sheahan, S. L., Martin, S. S., Hendricks, J., Robbins, C. A., \& Johnson, J. A. (1994). Predictors of medication noncompliance in a sample of older adults. Clinical Therapeutics, 16, 110-117.

*Corden, Z. M., Bosley, C. M., Rees, P. J., \& Cochrane G. M. (1997). Home nebulized therapy for patients with COPD: Patient compliance with treatment and its relation to quality of life. Chest, 112, 1278-1282.

*Cummings, K. M., Kirscht, J. P., Binder, L. R., \& Godley, A. J. (1982). Determinants of drug treatment maintenance among hypertensive persons in inner city Detroit. Public Health Reports, 97, 99-106.

Da Costa, D., Clarke A. E., Dobkin, P. L., Senecal, J. L., Fortin, P. R., Danoff, D. S., et al., (1999). The relationship between health status, social support and satisfaction with medical care among patients with systemic lupus erythematosus. International Journal for Quality in Health Care, 11, 201-207.

*Davis, C. L., Delamater, A. M., Shaw, K. H., La Greca, A. M., Eidson, M. S., Perez-Rodriguez, J. E., \& Nemery, R. (2001). Parenting styles, regimen adherence, and glycemic control in 4- to 10-year-old children with diabetes. Journal of Pediatric Psychology, 26, 123-129.

*Davis, M. S. (1968). Variations in patients' compliance with doctors' advice: An empirical analysis of patterns of communication. American Journal of Public Health, 58, 274-288.

*De Geest, S., Borgermans, L., Gemotes, H., Abraham, I., Vlamincs, H., Evers, G., et al., (1995). Incidence, determinants, and consequences of subclinical noncompliance with immunosuppressive therapy in renal transplant recipients. Transplantation, 59, 340-347.

*Dervin, J. V., Stone, D. L., \& Beck, C. H. (1978). The no-show patient in the model family practice unit. Journal of Family Practice, 7, 11771180.

Devine, E. C., \& Pearcy, J. (1996). Meta-analysis of the effects of psychoeducational care in adults with chronic obstructive pulmonary disease. Patient Education and Counseling, 29, 167-178.

*Diehl, A. K., Bauer, R. L., \& Sugarek, N. J. (1987). Correlates of medication compliance in non-insulin-dependent diabetes mellitus. Southern Medical Journal, 80, 332-335.

DiMatteo, M. R. (1994). Enhancing patient adherence to medical recommendations. Journal of the American Medical Association, 271, 79-83.

DiMatteo, M. R. (1999). The role of communication and physician-patient collaboration: Enhancing adherence with psychiatric medication. In J. Guimon, W. Fischer, \& N. Sartorius (Eds.), The image of madness (pp. 222-230). Basel, Switzerland: Karger.

DiMatteo, M. R. (2000). Practitioner-family-patient communication in pediatric adherence: Implications for research and clinical practice. In D. Drotar (Ed.), Promoting adherence to medical treatment in childhood chronic illness: Concepts, methods, and interventions (pp. 237-258). Mahwah, NJ: Erlbaum.

DiMatteo, M. R. (2004). Variations in patients' adherence to medical recommendations: A quantitative review of 50 years of research. Medical Care, 42(3).

DiMatteo, M. R., Giordani, P. J., Lepper, H. S., \& Croghan, T. W. (2002). Patient adherence and medical treatment outcomes: A meta-analysis. Medical Care, 40, 794-811.

DiMatteo, M. R., \& Hays, R. D. (1981). Social support and serious illness. 
In B. H. Gottlieb (Ed.), Social networks and social support (pp. 117148). Beverly Hills: Sage.

*DiMatteo, M. R., Hays, R. D., Gritz, E. R., Bastani, R., Crane, L., Elashoff, R., et al. (1993). Patient adherence to cancer control regimens: Scale development and initial validation. Psychological Assessment, 5, 102-112.

DiMatteo, M. R., Lepper, H. S., \& Croghan, T. W. (2000). Depression is a risk factor for noncompliance with medical treatment: A meta-analysis of the effects of anxiety and depression on patient adherence. Archives of Internal Medicine, 160, 2101-2107.

DiMatteo, M. R., \& Martin, L. R. (2002). Health psychology. Boston: Allyn \& Bacon.

*Doherty, W. J., Schrott, H. G., Metcalf, L., \& Iasiello-Vailas, L. (1983). Effect of spouse support and health benefits on medication adherence. Journal of Family Practice, 17, 837-841.

Druley, J. A., \& Townsend, A. L. (1998). Self-esteem as a mediator between spousal support and depressive symptoms: A comparison of healthy individuals and individuals coping with arthritis. Health Psychology, 17, 255-261.

*Duda, J. L., Smart, A. E., \& Tappe, M. K., (1989). Predictors of adherence in the rehabilitation of athletic injuries: An application of personal investment theory. Journal of Sports and Exercise Psychology, 11, 367-381.

Dunbar-Jacob, J., \& Schlenk, E. (2001). Patient adherence to treatment regimen. In A. Baum, T. A. Revenson, \& J. E. Singler (Eds.), Handbook of health psychology (pp. 571-580). Mahwah, NJ: Erlbaum.

*Eddy, M. E., Carter, B. D., Kronenberger, W. G., Conradsen, S., Eid, N. S., Bourland, S. L., et al. (1998). Parent relationships and compliance in cystic fibrosis. Journal of Pediatric Health Care, 4, 196-202.

*Eisen, S. A., Miller, D. K., Woodward, R. S., Spitznagel, E., \& Przybeck, T. R. (1990). The effect of prescribed daily dose frequency on patient medication compliance. Archives of Internal Medicine, 150, 1881-1884.

*Feinberg, J. (1992). Effect of the arthritis health professional on compliance with use of resting hand splints by patients with rheumatoid arthritis. Arthritis Care Research, 5, 17-23.

*Finnegan, D. L., \& Suler, J. R. (1984). Psychological factors associated with maintenance of improved health behaviors in postcoronary patients. Journal of Psychology, 119, 87-94.

Fontana, A. F., Kerns, R. D., Rosenberg, R. L, \& Colones, K. L. (1989). Support, stress, and recovery from coronary heart disease: A longitudinal causal model. Health Psychology, 8, 175-193.

*Foster, C. L., Byron, M., \& Eiser, C. (1998). Correlates of well-being in mothers of children and adolescents with cystic fibrosis. Child: Care, Health, and Development, 1, 41-56.

*Funke, B. L., \& Nicholson, M. E., (1993). Factors affecting patient compliance among women with abnormal Pap smears. Patient Education and Counseling, 20, 5-15.

*Gilbar, O. (1990). Is there a relationship between family environment and dropping out of chemotherapy. Journal of Psychosocial Oncology, 8, 99-107.

*Glasgow, R. E., Toobert, D. J., Riddle, M., Donnely, J., Mitchell, D. L., \& Calder, D. (1989). Diabetes-specific social learning variables and self-care behaviors among persons with type II diabetes. Health Psychology, 8, 285-303.

*Goldman, L. Freidin, R., Cook, E. F., Eigner, J., \& Grinch, P. (1982). A multivariate approach to the prediction of no-show behavior in a primary care center. Archives of Internal Medicine, 142, 563-567.

Goodenow, C., Reisine, S. T., \& Grady, K. E. (1990). Quality of social support and associated social and psychological functioning in women with rheumatoid arthritis. Health Psychology, 9, 266-284.

*Gordillo, V., Del Amo, J., Soriano, V., \& Gonzalez-Lahoz, J. (1999). Sociodemographic and psychological variables influencing adherence to antiretroviral therapy. AIDS, 13, 1763-1769.

*Grady, K. L., Jalowiec, A., \& White-Williams, C. (1998). Patient com- pliance at one year and two years after heart transplantation. Journal of Heart and Lung Transplantation, 4, 383-394.

*Grady, K. L., Russel, K. M., Srinivasan, S., Costanzo, M. R., \& Pifarre, R. (1993). Patient compliance with annual diagnostic testing after heart transplantation. Transplantation Proceedings, 25, 2978-2980.

Hagedoorn, M., Kuijer, R. G., Buunk, B. P., DeJong, G. M., Wobbes, T., \& Sanderman, R. (2000). Marital satisfaction in patients with cancer: Does support from intimate partners benefit those who need it most? Health Psychology, 19, 274-282.

*Hanson, C. L., Henggler, S. W., \& Burghen, G. A. (1987). Social competence and parental support as mediators of the link between stress and metabolic control in adolescents with insulin-dependent diabetes mellitus. Journal of Consulting and Clinical Psychology, 55, 529-533.

*Hanson, C. L., Henggler, S. W., Harris, M. A., Cigrang, J. A, Schinkel, A. M., Rodrigue, J. R., et al. (1992). Contributions of sibling relations to the adaption of youths with insulin dependent diabetes mellitus. Journal of Consulting and Clinical Psychology, 60, 104-112.

*Hao, D., Seidel, J., Brant, R., Alexander, F., Ernst, D. S., Summers, N., et al. (1998). Compliance of clinical stage I nonseminomatous germ cell tumor patients with surveillance. Journal of Urology, 3, 768-771.

*Hardy, M. C. (1948). Follow-up of medical recommendations. Journal of the American Medical Association, 136, 20-27.

*Hauser, S. T., Jacobsen, A. M, Lavori, P., Wolfsdorf, J. I., Herskowitz, R. D., Milley, J. E., et al. (1990). Adherence among children and adolescents with insulin-dependent diabetes mellitus over a four-year longitudinal follow-up: II. Immediate and long-term linkages with the family milieu. Journal of Pediatric Psychology, 15, 527-542.

Hedges, L. V., \& Vevea, J. L. (1998). Fixed-and random-effects models in meta-analysis. Psychological Methods, 3, 486-504.

*Heiby, E. M., Gafarian, C. T., \& McCann, S. C. (1989). Situational and behavioral correlates of compliance to a diabetic regimen. Journal of Compliance in Health Care, 2, 101-116.

Heitzmann, C. A., \& Kaplan, R. M. (1988). Assessment of methods for measuring social support. Health Psychology, 7, 75-109.

Helgeson, V. S., \& Cohen, S. (1996). Social support and adjustment to cancer: Reconciling descriptive, correlational, and intervention research. Health Psychology, 15, 135-148.

*Hershey J. C., Morton, B. G., Davis, J. B., \& Reichgott, M. J. (1980). Patient compliance with antihypertensive medication. American Journal of Public Health, 70, 1081-1089.

*Hilbert, G. A. (1985). Spouse support and myocardial infarction patient compliance. Nursing Research, 34, 217-220.

*Hitchcock, P. B., Brantley, P. J., Jones, G. N., \& McKnight, G. T. (1992). Stress and social support as predictors of dietary compliance in hemodialysis patients. Behavioral Medicine, 18, 13-20.

Holahan, C. J., Moos, R. H., Holahan, C. K., \& Brennan, P. L. (1995). Social support, coping, and depressive symptoms in a late-middle-aged sample of patients reporting cardiac illness. Health Psychology, 14, 152-163.

*Horwath, C. C., \& Worsley, A. (1991). Dietary habits of elderly persons with diabetes. Journal of the American Dietetic Association, 91, 553557.

Howell, D. C. (1997). Statistical methods for psychology (4th ed.). Belmont, CA: Duxbury Press.

*Hulka, B. S., Cassel, J. C., Kupper, L. L., \& Burdette, J. A. (1976). Communication, compliance, and concordance between physicians and patients with prescribed medications. American Journal of Public Health, 66, 847-853.

Hunt, M. (1997). How science takes stock: The story of meta-analysis. New York: Russell Sage.

Ioannidis, J. P., Cappelleri, J. C., \& Lau, J. (1998). Issues in comparisons between meta-analyses and large trials. Journal of the American Medical Association, 279,1089-1093.

*Irvine, J., Baker, B., Smith, J., Jandciu, S., Paquette, M., Cairns, J., et al. 
(1999). Poor adherence to placebo or amiodarone therapy predicts mortality: Results from the CAMIAT study. Psychosomatic Medicine, 4, 566-575.

*Irwin, C. E., Millstein, S. G., \& Shafer, M. B. (1981). Appointment keeping behavior in adolescents. Journal of Pediatrics, 99, 799-802.

*Jamison, R. N., Lewis, S., \& Burish, T. G. (1986). Cooperation with treatment in adolescent cancer patients. Journal of Adolescent Health Care, 7, 162-167.

*Jones, P. K., Jones, S. L., \& Katz, J. (1987). Improving follow-up among hypertensive patients using a Health Belief Model intervention. Archives of Internal Medicine, 147, 1557-1560.

*Jones, P. K, Jones, S. L., \& Katz, J. (1990). A randomized trial to improve compliance in urinary tract infection patients in the emergency department. Annals of Emergency Medicine, 19, 16-20.

*Jung, J. (1990). Global versus health-specific social support and match of preferred and perceived social support levels in relationship to compliance and blood pressure of hypertensives. Journal of Applied Social Psychology, 20, 1103-1111.

*Kalichman, S. C., Ramachandran, B., \& Catz, S. (1999). Adherence to combination antiretroviral therapies in HIV patients of low health literacy. Journal of General Internal Medicine, 5, 267-273.

Kaplan, R. M., \& Hartwell, S. L. (1987). Differential effects of social support and social networks on physiological and social outcomes in men and women with type II diabetes mellitus. Health Psychology 6, 387-398.

*Kaufman, F. R., Halvorson, M., \& Carpenter, S. (1999). Association between diabetes control and visits to a multidisciplinary pediatric diabetes clinic. Pediatrics, 5, 948-951.

*Kiley, D. J., Lam, C. S., \& Pollak, R. (1993). A study of treatment compliance following kidney transplantation. Transplantation, 55, 5156.

*Kimmel, P. L., Peterson, R. A., Weihs, K. L., Shidler N., Simmens, S. J., Alleyne S., et al. (2000). Dyadic relationship conflict, gender, and mortality in urban hemodialysis patients. Journal of the American Society of Nephrology, 11, 1518-1525.

King, K. B., Reis, H. T., Porter, L. A., \& Norsen, L. H. (1993). Social support and long-term recovery from coronary artery surgery: Effects on patients and spouses. Health Psychology, 12, 56-63.

*Kouris, A., Wahlqvist, M. L., \& Worsley A. (1988). Characteristics that enhance adherence to high-carbohydrate/high-fiber diets by persons with diabetes. Journal of the American Dietetic Association, 88, 1422-1425.

*Kremers, S. P., Mesters, I., Pladdet, I. E., van den Borne, B., \& Stockbrugger, R. W. (2000). Participation in a sigmoidoscopic colorectal cancer screening program: A pilot study. Cancer Epidemiology, Biomarkers and Prevention, 9, 1127-1130.

Kulik, J. A., \& Mahler, H. I. (1989). Social support and recovery from surgery. Health Psychology, 8, 221-238.

*Kulik, J. A., \& Mahler, H. I. (1993). Emotional support as a moderator of adjustment and compliance after coronary artery bypass surgery. Journal of Behavioral Medicine, 16, 45-63.

*Kyngas, H. (2000). Compliance with health regimen of adolescents with epilepsy. Seizure, 9, 598-604.

*Kyngas, H., Hentinen, M., \& Barlow, J. H. (1998). Adolescents' perceptions of physicians, nurses, parents and friends: Help or hindrance in compliance with diabetes self care? Journal of Advanced Nursing, 27, $760-769$.

*Kyngas, H., \& Ladenpera, T. (1999). Compliance of patients with hypertension and associated factors. Journal of Advanced Nursing, 29, 832839

*La Greca, A. M., Auslander, W. F., Greco, P., Spetter, D., Fisher, E. B., \& Santiago, J. V. (1995). I get by with a little help from my family and friends: Adolescents' support for diabetes care. Journal of Pediatric Psychology, 20, 449-476.

La Greca, A. M., Bearman, K. J., \& Moore, H. (2002). Peer relations of youth with pediatric conditions and health risks: Promoting social support and healthy lifestyles. Journal of Developmental and Behavioral Pediatrics, 23, 271-280.

*Lebovits, A. H., Strain, J. J., Schleifer, S. J., Tanaka, J. S., Bhardwaji, S., \& Messe, M. R. (1990). Patient noncompliance with self-administered chemotherapy. Cancer, 65, 17-22.

*Leduc, N., Tannenbaum, T. N., Bergman, H., Champagne, F., Clarfield, A. M., \& Kogan, S. (1998). Compliance of frail elderly with health services prescribed at discharge from an acute-care geriatric ward. Medical Care, 36, 904-914.

*Lerman, C., Hanjani, P., Caputo, C., Miller, S., Delmoor, E., Nolte, S., et al. (1992). Telephone counseling improves adherence to coloscopy among lower-income minority women. Journal of Clinical Oncology, 10, 330-333.

*Levine, A. M., Richardson, J. L., Marks, G., Chan, K., Graham, J., Selser, J. N., et al. (1987). Compliance with oral drug therapy in patients with hematologic malignancy. Journal of Clinical Oncology, 5, 1469-1476.

Lewis, M. A., \& Rook, K. S. (1999). Social control in personal relationships: Impact on health behaviors and psychological distress. Health Psychology, 18, 63-71.

*Lindeman, M., \& Behm, K. (1999). Cognitive strategies and self-esteem as predictor of brace-wear noncompliance in patients with idiopathic scoliosis and kyphosis. Journal of Pediatric Orthopedics, 19, 493-499.

*Lorenc, L., \& Branthwaite, A. (1993). Are older adults less compliant with prescribed medication than younger adults? British Journal of Clinical Psychology, 32, 485-492.

*Macdonald, M. E., Hagberg, A. M., \& Grossman, B. J. (1963). Social factors in relation to participation in follow-up care of rheumatic fever. Journal of Pediatrics, 62, 503-513.

Martin, R., Davis, G. M, Baron, R. S., Suls, J., \& Blanchard, E. B. (1994), Specificity in social support: Perceptions of helpful and unhelpful provider behaviors among irritable bowel syndrome, headache, and cancer patients. Health Psychology, 13, 432-439.

*Mattar, M. E., Markello, J., \& Sumner, J. Y. (1975). Pharmaceutic factors affecting pediatric compliance. Pediatrics, 55, 101-108.

McBride, C. M., Pollak, K. I., Lyna, P., Lipkus, I. M., Samsa, G. P., \& Bepler, G. (2001). Reasons for quitting smoking among low-income African American smokers. Health Psychology, 20, 334-340.

*McCaul, K. D., Glasgow, R. E., \& Schafer, L. C. (1987). Diabetes regimen behaviors: Predicting adherence. Medical Care, 25, 868-881.

Meyer, T. J., \& Mark, M. M. (1995). Effects of psychosocial interventions with adult cancer patients: A meta-analysis of randomized experiments. Health Psychology, 14, 101-108.

*Miller-Johnson, S., Emery, R. E., Marvin, R. S., Clarke, W., Lovinger, R., \& Martin, M. (1994). Parent-child relationships and the management of insulin-dependent diabetes mellitus. Journal of Consulting and Clinical Psychology, 62, 603-610.

*Morgan, P. J., Christensen, A. J., \& Lawton, W. J. (1997). Social support and conscientiousness in hemodialysis adherence. Annals of Behavioral Medicine, 19, 333-338.

Mullen, P. D., Mains, D. A., \& Velez, R. (1992). A meta-analysis of controlled trials of cardiac patient education. Patient Education and Counseling, 19, 143-162.

*Murphy, L. M. B., Thompson, R. J., \& Morris, M. A. (1997). Adherence behavior among adolescents with type I insulin-dependent diabetes mellitus: The role of cognitive appraisal processes. Journal of Pediatric Psychology, 22, 811-825.

*Mushlin, A. I., \& Appel, F. A. (1977). Diagnosing potential noncompliance: Physician's ability in a behavioral dimension of medical care. Archives of Internal Medicine, 137, 318-321.

*Nolan, T., Debelle, G., Oberklaid, F., \& Coffrey, C. (1991). Randomized trial of laxatives in treatment of childhood encopresis. Lancet, 339, $523-527$. 
*O'Brien, M. E. (1980). Hemodialysis regimen compliance and social environment: A panel analysis. Nursing Research, 29, 250-255.

*Parkin, D. M., Henry, C. R., Quirk, J., \& Crooks, J. (1976). Deviation from prescribed drug treatment after discharge from hospital. British Medical Journal, 2, 686-688.

*Patterson, J. M., Budd, J., Goetz, D., \& Warrick, W. J. (1993). Family correlates of a 10-year pulmonary health trend in cystic fibrosis. Pediatrics, 91, 383-389.

Penninx, B. W. J. H., van Tilburg, T., Boeke, A. J. P., Deeg, D. J. H., Kriegsman, D. M. W., \& van Eijk, J. T. M. (1998). Effects of social support and personal coping resources on depressive symptoms: Different for various chronic diseases? Health Psychology, 17, 551-558.

Pilisuk, M., Boylan, R., \& Acredolo, C. (1987). Social support, life stress, and subsequent medical care utilization. Health Psychology, 6, 273-288.

*Rand, C. S., Nides, M., Crowles, M. K., Wise, R. A., \& Connett, J. (1995). Long-term metered-dose inhaler adherence in a clinical trial. American Journal of Respiratory and Critical Care Medicine, 152, $580-588$

Reifman, A. (1995). Social relationships, recovery from illness, and survival: A literature review. Annals of Behavioral Medicine, 17, 124-131.

Revenson, T. A., \& Majerovitz, D. (1991). The effects of chronic illness on the spouse: Social resources as stress buffers. Arthritis Care and Research, 4, 63-72.

Revicki, D. A., \& May, H. J. (1985). Occupational stress, social support, and depression. Health Psychology, 4, 61-77.

*Rich, M. W., Gray, D. B., Beckham, V., Wittenberg, C., \& Luther, P. (1996). Effect of a multidisciplinary intervention on medication compliance in elderly patients with congestive heart failure. American Journal of Medicine, 101, 270-276.

*Rodriquez, A., Diaz, M. Colon, A., \& Santiago-Delpin, E. A. (1991). Psychosocial profile of noncompliant transplant patients. Transplantation Proceedings, 23, 1807-1809.

Rosenberg, S. J., Hayes, J. R., \& Peterson, R. A. (1987). Revising the seriousness of illness rating scale: Modernization and re-modernization. International Journal of Psychiatry in Medicine, 17, 85-92.

Rosenthal, R. (1979). The "file drawer problem" and tolerance for null results. Psychological Bulletin, 86, 638-641.

Rosenthal, R. (1991). Meta-analytic procedures for social research (2nd ed). Newbury Park, CA: Sage.

Rosenthal, R., \& DiMatteo, M. R. (2001). Meta-analysis: Recent developments in quantitative methods for literature reviews. Annual Review of Psychology, 52, 59-82.

Rosenthal, R., \& DiMatteo, M. R. (2002). Meta-analyses. In J. Wixted (Ed.), Steven's handbook of experimental psychology: Third edition, Volume 4. Methodology (pp. 391-428). New York: Wiley.

Rosenthal, R., \& Rosnow, R. L. (1991). Essentials of behavioral research (2nd ed). New York: McGraw-Hill.

Rosenthal, R., Rosnow, R. L., \& Rubin, D. B. (2000). Contrasts and effect sizes in behavioral research: A correlational approach. New York: Cambridge University Press.

*Rosilio, M., Cotton, J. B., Wieliczko, M. C., Gendrault, B., Carel, J. C., Couvaras, O., et al. (1998). Factors associated with glycemic control. A cross-sectional nationwide study in 2,579 French children with type 1 diabetes. Diabetes Care, 21, 1146-1153.

*Schafer, L. C., Glascow, R. E., McCaul, K. D., \& Dreher, M. (1983). Adherence to IDDM Regimens: Relationship to psychosocial variables and metabolic control. Diabetes Care, 6, 493-498.

*Schatz, P. E., (1988). An evaluation of the components of compliance in patients with diabetes. Journal of the American Dietetic Association, 88, $708-712$

Schneider, M. S., Friend, R., Whitaker, P., \& Wadhwa, N. K. (1991). Fluid noncompliance and symptomatology in end-stage renal disease: Cognitive and emotional variables. Health Psychology, 10, 209-215.

*Schoenberg, N. E. (1998). The relationship between perceptions of social support and adherence to dietary recommendations among AfricanAmerican elders with hypertension. International Journal of Aging \& Human Development, 47, 279-297.

Shumaker, S. A., \& Hill, D. R. (1991). Gender differences in social support and physical health. Health Psychology, 10, 102-111.

*Schwartz, D., Wang, M., Zeitz, L., \& Goss, M. E. W. (1962). Medication errors made by elderly, chronically ill patients. American Journal of Public Health, 52, 2018-2029.

Seeman, T. E., Lusignolo, T. M., Albert, M., \& Berkman, L. (2001). Social relationships, social support, and patterns of cognitive aging in healthy, high-functioning older adults: MacArthur Studies of Successful Aging. Health Psychology, 20, 243-255.

*Shapiro, P. A., Williams, D. L., Foray, A. T., Gelman, I. S., Wukick, N., \& Sciacca, R. (1995). Psychosocial evaluation and prediction of compliance problems and morbidity after heart transplantation. Transplantation, 60, 1462-1466.

*Sherbourne, C. D., Hays, R. D., Ordway, L., DiMatteo, M. R., \& Kravits, R. L. (1992). Antecedents of adherence to medical recommendations: Results from the Medical Outcomes Study. Journal of Behavioral Medicine, 15, 447-468.

*Sherwood, J. (1983). Compliance behavior in hemodialysis patients and the role of the one family. Family Systems Medicine, 1, 60-72.

*Simon, J. A., Browner, W. S., \& Mangano, D. T. (1992). Predictors of smoking relapse after noncardiac surgery. American Journal of Public Health, 82, 1235-1237.

*Singh, N., Berman, S. M., Swindells, S., Justice, J. C., Mohr, J. A., Squier, C., et al. (1999). Adherence of human immunodeficiency virus-infected patients to antiretroviral therapy. Clinical Infectious Diseases, 29, $824-$ 830.

*Specht, E. M., \& Bourguet, C. C. (1994). Predictors of nonattendance at the first newborn health supervision visit. Clinical Pediatrics, 33, 273 279.

*Stanton, A. L. (1987). Determinants of adherence to medical regimens by hypertensive patients. Journal of Behavioral Medicine, 10, 377-394.

*Steidl, J. H., Finkelstein, F. O., Wexler, J. P., Feigenbaum, H., Kitsen, J., Kliger, A. S., et al. (1980). Medical condition, adherence to treatment regimens, and family functioning. Archives of General Psychiatry, 37, $1025-1027$.

Stone, A. A., Mezzacappa, E. S., Donatone, B. A., \& Gonder, M. (1999). Psychosocial stress and social support are associated with prostatespecific antigen levels in men: Results from a community screening program. Health Psychology, 18, 482-486.

*Taal, E., Rasker, J. J., Seydel, E. R., \& Wiegman, O. (1993). Health status, adherence with health recommendations, self-efficacy and social support in patients with rheumatoid arthritis. Patient Education and Counseling, 20, 63-76.

Taylor, S. E., Falke, R. L., Shoptaw, S. J., \& Lichtman, R. R. (1986). Social support, support groups, and the cancer patient. Journal of Consulting and Clinical Psychology, 54, 608-615.

*Tebbi, C. K., Cummings, K. M., Zevon, M. A., Smith, L., Richards, M., \& Mallon, J. (1986). Compliance of pediatric and adolescent cancer patients. Cancer, 58, 1179-1184.

*Teichman, B. J., Burker, E. J., Weiner, M., \& Egan, T. M. (2000). Factors associated with adherence to treatment regimens after lung transplantation. Progress in Transplantation, 10, 113-121.

*Tirrell, B. E., \& Hart L. K. (1980). The relationship of health beliefs and knowledge to exercise compliance in patients after coronary bypass. Heart \& Lung, 9, 487-493.

*Turner, J., Wright, E., Mendella, L., \& Anthonisen, N. (1995). Predictors of patient adherence to long-term home nebulizer therapy for COPD. Chest, 108, 394-400.

Uchino, B, N., Cacioppo, J. T., \& Kiecolt-Glaser, J. K. (1996). The relationship between social support and physiological processes: A 
review with emphasis on underlying mechanisms and implications for health. Psychological Bulletin, 119, 488-531.

Umberson, D. (1987). Family status and health behaviors: Social control as a dimension of social integration. Journal of Health and Social Behavior, 28, 306-319.

Vitaliano, P. P., Scanlan, J. M., Zhang, J., Savage, M. V., Brunnett, B., Barefoot, J., et al. (2001). Are the salutogenic effects of social supports modified by income? A test of an "added value hypothesis." Health Psychology, 20, 155-165.

*Walders, N., Drotar, D., \& Kercsmar, C. (2000). The allocation of family responsibility for asthma management tasks in African-American adolescents. Journal of Asthma, 37, 89-99.

Wallston, B. S., Alagna, S. W., DeVellis, B. M., \& DeVellis, R. F. (1983). Social support and physical health. Health Psychology, 2, 367-391.

*Weinman, M. L., Smith, P. B., \& Buzi, R. S. (1996). Compliance with follow-up among adolescent males with sexually transmitted diseases. Psychology Reports, 78, 840-842.

*Wiebe, J. S., \& Christensen, A. J. (1997). Health beliefs, personality, and adherence in hemodialysis patients: An interactional perspective. Annals of Behavioral Medicine, 19, 30-35.

*Williams, G. C., Freedman, Z. R., \& Deci, E. L. (1998). Supporting autonomy to motivate patients with diabetes for glucose control. Diabetes Care, 10, 1644-1651.

*Woller, W., Kruse, J., Winter, P., Mans, E. J., \& Alberti, L. (1993). Cortisone image and emotional support by key figures in patients with bronchial asthma. Psychotherapy and Psychsomatics, 59, 190-196.

*Wysocki, T., Hough, B. S., Ward, K. M., \& Green, L. B. (1992), Diabetes mellitus in the transition to adulthood: Adjustment, selfcare, and health status. Journal of Developmental \& Behavioral Pediatrics, 13, 194-201.

\section{ORDER FORM}

Start my 2004 subscription to Health Psychology! ISSN:0278-6133

\section{$\$ 56.00$, APA Member/Affiliate $\$ 88.00$, INDIVIDUAL NoNMEMber \\ $\$ 283.00$, Institution \\ In DC add $5.75 \%$ / In MD add $5 \%$ sales tax}

Total Amount Enclosed

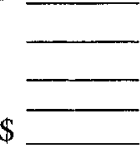

Subscription orders must be prepaid. (Subscriptions are on a calendar year basis only.) Allow 4-6 weeks for delivery of the first issue. Call for international subscription rates.

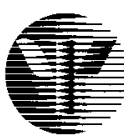

AMERICAN PSYCHOLOGICAL ASSOCIATION

Washington, DC 20002-4242
SEND THIS ORDER FORM TO:

American Psychological Association

Subscriptions

750 First Street, NE

Or call (800) 374-2721, fax (202) 336-5568.

TDD/TTY (202) 336-6123.

For subscription information, e-mail: subscriptions@apa.org
Send me a FREE Sample Issue

Check enclosed (make payable to APA)

Charge my: $\bigcirc$ VISA $\bigcirc$ MasterCard $\underset{\text { Express }}{\text { American }}$

Cardholder Name

Card No. Exp. Date

Signature (Required for Charge)

BILLING ADDRESS

City__ State __ Zip___
Daytime Phone____
E-mail

SHIP TO:

Name

Address

City__ State __ Zip

APA Member \# 